Framework programme (which is now used by over a third of UK practices) to identify and care for such patients. ${ }^{10}{ }^{11}$ The box shows a possible scheme to use advance care planning to improve end of life care.

Realistic information, sensitively provided, helps patients and their families to maintain a feeling of normality and allows them to develop new coping strategies. Such discussions engender hope. Such hope is not for a cure but for understanding the process of dying and for reassurance that support will be given during a variety of eventualities. Calman described quality of life in terms of the gap between patients' expectations and reality. ${ }^{12}$ Our role may be to negotiate realistic changes in expectation (by discussing likely trajectories, prognosis, and advance care planning) and concurrent improvements in reality (with good symptom control and support services) to improve quality of life in the final months and weeks.

Davison and Simpson's study is a small but important step in enhancing our understanding of the importance of notions of hope, even when to the outsider it seems that all hope is lost. Their findings need to be confirmed in other populations (the patients

1 Murray SA, Kendall M, Boyd K, Sheikh A. Illness trajectories and palliative care. BMJ 2005;330:1007-11.

2 Davison SN, Simpson C. Hope and advance care planning in patient with end stage renal disease: qualitative interview study. BMJ doi: 10.1136/bmj.38965.626250.55.

3 Sanders C, Seymour J, Clarke A, Gott M, Welton M. Development of a peer education programme for advance end of life care planning. Int Palliative Nurs 2006;12:214-23.

4 Help the Aged. Planning for choice in end of life care. London: Help the Aged, 2006. www.helptheaged.org.uk/NR/rdonlyres/6C50EADE-2AB74025-9368-6787B5A23F08/0/planning_for_choice_in_endoflife.pdf (accessed 13 Oct 2006).

5 Hunter New England NSW Health. Advance care planning. www.hnehealth.nsw.gov.au/advanced_care_planning (accessed 13 Oct 2006).

6 Fraser Health. Advance care planning. Let's talk. www.fraserhealth.ca/ HealthInfo/AdvanceCarePlanning/Default.htm (accessed 13 Oct 2006) studied were almost exclusively white) and through implementation studies to evaluate how best the proactive approach improves outcomes of patients. That said, considerable evidence supports the integration of advance care planning into routine practice as part of good care for all people with progressive life threatening illnesses. Planning for death with our patients may be an uncomfortable concept but is likely to engender hope rather than dispel it.

Scott A Murray St Columba's Hospice professor of primary palliative care

(Scott.Murray@ed.ac.uk)

Aziz Sheikh professor of primary care research and development

Primary Palliative Care Research Group, Division of Community Health Sciences: General Practice Section, University of Edinburgh, Edinburgh EH8 9DX

Keri Thomas national clinical lead, palliative care (generalist)

NHS End of Life Care Programme England, John Taylor Hospice, Birmingham B24 0DF

Competing interests: None declared.

National Hospice and Palliative Care Organisation. Advance care planning. www.caringinfo.org/i4a/pages/index.cfm?pageid $=3278$ (accessed 13 Oct 2006).

8 Gomes B, Higginson IJ. Factors influencing death at home in terminally ill patients with cancer: systematic review. BMJ 2006;332:515-21.

Department of Health. The Mental Capacity Act. London: DoH, 2005. www.dh.gov.uk/PublicationsAndStatistics/Bulletins/ChiefExecutive Bulletin/ChiefExecutiveBulletinArticle/fs/en?CONTENT_ID =4108436 \&chk $=$ z0Ds8 $/$ (accessed 13 Oct 2006).

10 Department of Health. The gold standards framework. London: DoH, 2005 www.goldstandardsframework.nhs.uk/gp_contract.php (accessed 13 Oct 2006).

11 Thomas K. Caring for the dying at home. Companions on a journey. Oxford. Radcliffe Medical Press, 2003.

12 Calman KC. Quality of life in cancer patients-an hypothesis. J Med Ethics 1984:10:124-7.

doi 10.1136/bmj.39009.569861.80

\title{
Age related macular degeneration
}

\section{Better tools are needed to measure quality of life and visual outcomes}

$\mathrm{W}$ et (also known as neovascular or exudative) age related macular degeneration is a common condition of poorly understood aetiology that affects around two million elderly people in Europe. ${ }^{1}$ In the United Kingdom, in about a quarter of a million people wet macular degeneration causes bilateral visual impairment of sufficient severity that they are registered as partially sighted or blind. ${ }^{2}$ If only one eye is affected the onset of disease may go unnoticed by the patient. Wet macular degeneration is usually bilateral though, and when the second eye becomes affected the impact on the patient is devastating. ${ }^{3}$

Good vision is often taken for granted. It is an important prerequisite for a socially fulfilling and active lifestyle. Wet macular degeneration affecting both eyes has serious consequences for quality of life. The psychosocial and functional impact of sight loss due to this condition is reviewed in a paper by Mitchell and Bradley commissioned by the Interna- major problem is defining quality of life; this is highlighted by the lack of consensus in various questionnaires that aim to measure it. ${ }^{5}$ Mitchell and Bradley question the relevance of current instruments used to monitor health status, quality of life, and visual functioning in patients with age related macular degeneration. This is supported by the fact that popular instruments for measuring health status-such as the medical outcomes study short form 36 (SF-36), health utilities index 3 (HUI3), and EuroQol (EQ-5D)-do not capture the effects of sight loss on quality of life. ${ }^{4}$

Many people with neovascular macular degeneration report excellent health, either because the disease affects only one eye or they do not perceive sight loss as a decline in their general health status. Despite this, they are shocked by how rapidly loss of sight progresses and frightened at the thought of going blind and thus losing their independence, features that are not captured by existing instruments for measuring health status. Even when these instruments are used in 
patients with poor physical health, any contribution from impaired vision is difficult to distinguish from that of comorbid disorders. Health utility measures such as the standard gamble and time trade-off techniques are also inappropriate. ${ }^{4}$ Elderly people have problems understanding the hypothetical concepts of the percentage of risk of death that they would be prepared to accept to avoid chronic ill health or the number of years of life they would be prepared to trade for a perfect cure for their medical condition. Also such questions would be difficult for elderly people to answer given their shorter life expectancies.

Most visual functioning questionnaires assess the impact of visual loss on daily living but do not measure social or psychological functioning. ${ }^{4}$ Though some questionnaires-such as the National Eye Institute visual functioning questionnaire-do measure psychological aspects of visual impairment, ${ }^{6}$ they are unresponsive to small differences in visual acuity. The authors of the review recommend their own instrument the MacDQoL, ${ }^{7}$ which measures the impact of age related macular degeneration on quality of life and can discriminate between mild and moderate disease. The usefulness of this tool is difficult to assess, however, as what constitutes mild or moderate age related macular degeneration is not defined.

Vision is a complex neurosensory task mediated by both eyes, so that wet macular degeneration in one eye does not necessarily affect quality of life. The commonly measured surrogate marker visual acuity also correlates poorly with the severity of retinal changes. ${ }^{8}$ Many people develop adaptive strategies over time that cannot be captured in cross sectional studies and are difficult to control for even in longitudinal studies. Thus, the criticism that most existing visual functioning questionnaires lack the sensitivity to differentiate severity of disease would appear to be unduly harsh, as appropriately designed large longitudinal studies have not yet been undertaken.

Mitchell and Bradley state that despite the development of promising new treatments, ${ }^{10}$ none has used an effective measure of quality of life to evaluate benefit. Treatments that are unpleasant, need repeated administration, and cause adverse effects are likely to reduce quality of life even though they may improve visual acuity. An ideal instrument for use in wet macular degeneration will be responsive to changes in visual function and quality of life as well as capture satisfaction with treatment. Such an instrument is needed now.

Usha Chakravarthy professor of ophthalmology and vision sciences

(u.chakravarthy@qub.ac.uk)

Centre for Vision Science, Queen's University of Belfast, Belfast BT12 6BA

Competing interests: None declared.

1 Augood C, Vingerling J, deJong PT, Chakravarthy U, Seland J, Soubrane $\mathrm{G}$, et al. Prevalence of age-related maculopathy in older Europeans: the European eye study (EUREYE). Arch Ophthalmol 2006;123:529-35.

2 Evans JR, Fletcher AE, Wormald RP. Age-related macular degeneration causing visual impairment in people 75 years or older in Britain: an add-on study to the Medical Research Council trial of assessment and management of older people in the community. Ophthalmology 2005;111:513-7.

3 Slakter JS, Stur M. Quality of life in patients with age-related macular degeneration: impact of the condition and benefits of treatment. Surv degeneration: impact of the
Ophthalmol 2005;50:263-73.

4 Mitchell J, Bradley C. Quality of life in age-related macular degeneration. A review of the literature. http://amdalliance.org/documents/White $\% 20$ paper $\% 20$ amended $\% 20$ final $\% 20 \mathrm{fcr} \% 201909061$.pdf (accessed 19 Oct 2006)

5 Bradley C. Importance of differentiating health status from quality of life. Lancet 2001;357:7-8.

6 Mangionce CM, Berry S, Spritzer K, Janz NK, Klein R, Owsley C, et al. Identifying the content area for the 51-item National Eye Institute visual function questionnaire: results from focus groups with visually impaired persons. Arch Ophthalmol 1998:116:297-33.

7 Mitchell J, Bradley C. Design of an individualised measure of the impact of macular disease on quality of life: the MacDQoL. Qual Life Res 2004;13:1163-75.

8 Fletcher DC, Schuchard RA. Visual function in patients with choroidal neovascularization resulting from age-related macular degeneration: the importance of looking beyond visual acuity. Optom Vis Sci 2006:83:17889 .

9 Hogg RE, Curry E, Muldrew A, Winder J, Stevenson M, McClure M, et al. Identification of lesion components that influence visual function in age related macular degeneration. Br J Ophthalmol 2003;87:609-14.

10 Stone EM. A very effective treatment for neovascular macular degeneration. N Engl J Med 2006;355:1493-5.

doi $10.1136 /$ bmj.39009.366736.80

\title{
Spirometry in chronic obstructive pulmonary disease
}

\author{
Is available, yet underused in general practice
}

C hronic obstructive pulmonary disease affects about $1 \%$ of the total UK population ${ }^{1}$ and is a major cause of disability and mortality worldwide. Timely diagnosis and subsequent staging of severity of disease both require spirometry, which in theory can be performed by trained general practitioners (GPs) and their practice staff. ${ }^{2} 3$ However, numerous barriers impede the implementation of spirometry in primary care.

Several guidelines exist for the management of patients with chronic obstructive pulmonary disease, including those from the UK National Institute for Health and Clinical excellence (NICE) ${ }^{4}$ and the Global Initiative for Chronic Obstructive Lung Disease
(GOLD; www.goldcopd.com). All guidelines stress the central role of spirometry in diagnosing and managing the disease in primary care, but this does not guarantee that GPs will use this technique consistently in the care of patients with respiratory symptoms. ${ }^{5}$

Several models to provide spirometry test results exist, depending on local circumstances; these include regional primary care diagnostic services and hospital based lung function laboratories with open access for primary care patients. ${ }^{6}$ However, the most practical and timely solution is for GPs to have their own spirometer in the practice. ${ }^{7}$ In the United Kingdom about $80 \%$ of general practices own a spirometer, ${ }^{8}$ but these instruments are still scarce in large parts of the world, 